\title{
ANALISIS VISUAL SEJARAH DAN BUDAYA DALAM KOMIK LEGENDA SAWUNG KAMPRET
}

\author{
Henny Hidajat ${ }^{* 1}$ \\ ${ }^{1}$ Dosen Program Studi Desain Komunikasi Visual Universitas Bunda Mulia \\ Diterima: 3 Oktober 2018 /Disetujui: 12 Oktober 2018
}

\begin{abstract}
The research is discussing about visual appearance related to the history and cultural values in Indonesian comics with historical theme, with 'Legenda Sawung Kampret' comic serial as the case study. Through the visualization of the history and culture as described in the characterization, plot, place and time setting, tradition, or other things of those comics, a certain meaning can be evaluated whether it is proper to the historical fact.

Analythical process is implementing descriptive and qualitative techniques by taking 'Legenda Sawung Kampret' as an example of Indonesian historical theme comics. Based on the sample comic, an evaluation can be implemented on the basic visual elements and principles that support to deliver the historical and cultural content. Therefore, hopefully the historical and cultural content and the meaning reflected on the visualization can be analyzed.
\end{abstract}

Keyword: Comic, History, Culture

\begin{abstract}
ABSTRAK
Artikel ini membahas mengenai tampilan visual yang berkaitan dengan nilai-nilai sejarah dan budaya pada komik Indonesia yang bertema sejarah, dengan studi kasus komik serial 'Legenda Sawung Kampret' . Melalui tampilan visual tersebut dapat diangkat pemaknaan terhadap latar sejarah dan budaya yang disajikan dalam komik tersebut apakah sesuai dengan catatan sejarah yang terjadi. Oleh karena itu, penelitian ini bertujuan untuk menemukan implementasi penggambaran catatan sejarah dan budaya pada objek penelitian yaitu komik Indonesia bertema sejarah tersebut, baik melalui alur cerita, penokohan, setting tempat dan waktu, tradisi, serta hal-hal lainnya.

Analisis dilakukan secara kualitatif deskriptif dengan mengambil contoh kasus komik 'Legenda Sawung Kampret', yang merupakan komik bertema sejarah Indonesia yaitu pada periode kolonial Belanda. Berdasarkan contoh tersebut dapat dilakukan evaluasi terhadap unsur-unsur visual maupun unsur cerita yang mendukung penyampaian materi tentang sejarah tesebut. Dengan demikian dapat diharapkan hasil berupa analisis tentang penerapan latar sejarah dan budaya tersebut dalam visualisasi komik serta makna yang dapat diterima oleh pembacanya.
\end{abstract}

Kata Kunci : Komik, sejarah, budaya

\section{PENDAHULUAN}

Indonesia sebagai suatu bangsa memiliki perjalanan sejarah yang sangat panjang, sejak periode Prasejarah, masuknya pengaruh Hindu, Buddha, agama Islam hingga masuknya pengaruh bangsa Barat yang disertai dengan periode kolonialisme hingga akhirnya berhasil memproklamirkan kemerdekaan, bersama dengan local genius dari para pendahulu bangsa Indonesia, telah membangun kebudayaan dan tradisi yang beragam pada berbagai suku bangsa di Nusantara ini. Sementara itu periode kolonialisme telah memicu terjadinya proses konsolidasi sebagai suatu bangsa untuk mengatasi kolonialisme tersebut, hingga akhirnya para pendiri negara ini dapat membebaskan Indonesia dan membentuk suatu negara kesatuan walaupun pada dasarnya Indonesia memiliki beragam suku bangsa.

*email:_hhidajat@bundamulia.ac.id 
Untuk mengapresiasi dan mensyukuri segala keberagaman budaya dan proses kemerdekaan yang telah dicapai dengan segenap pengorbanan dan perjuangan para pendahulu bangsa Indonesia, maka perlu adanya upaya untuk mengenang dan mewariskan nilai-nilai tersebut kepada generasi penerus. Diharapkan mereka dapat menghargai segala kebudayaan dan tradisi serta kemerdekaan yang telah diraih, paling tidak dengan memahami sejarah maupun kebudayaan yang dimiliki secara lebih baik. Upaya untuk mengingatkan kembali sejarah dan kebudayaan kepada generasi muda perlu menggunakan media yang akrab dengan mereka. Salah satu media yang sangat populer adalah media bacaan komik. Selain berisi teks, komik juga dapat memberikan gambaran tentang sejarah maupun kebudayaan secara lebih detail sesuai fakta, yang dapat ditemukan melalui arsip dokumentasi dan catatan-catatan lainnya. Sementara itu komik merupakan media yang sangat dinamis dan cenderung digemari karena daya tariknya tidak hanya pada teks, namun juga pada tampilan visualnya.

Melalui tampilan visualnya, komik dapat menggambarkan tokoh dengan segenap karakter, ekspresi serta aksinya, latar tempat dan waktu terjadinya peristiwa, alur kejadian peristiwa yang menjadi fokus cerita, selain itu komik juga dapat menjelaskan alur cerita dengan lebih sistematis. Karakteristik benda, tokoh, setting serta atmosfer situasi menjadi tidak terlalu sulit dibayangkan karena adanya visualisasi.

Di Indonesia komik telah berkembang sejak periode 1930-an yang dimulai dengan perkembangan komik strip dan buku-buku komik bertema pahlawan super, yang banyak mengikuti buku-buku serupa di Amerika maupun Eropa. Tema tersebut lalu dilanjutkan dengan munculnya komik cerita silat yang mengangkat tokohtokoh laga lokal. Pada era 1970-80-an perkembangan komik Indonesia dapat ditandai dengan munculnya komik wayang, termasuk versi yang lebih populer yaitu komik Petruk-Gareng. Namun pada era 1990-an hingga awal 2000-an mulai jarang menemukan komik bertema sejarah dan kebudayaan Indonesia, sejalan dengan menurunnya pamor komik Indonesia yang cenderung kalah bersaing dengan komik asing, terutama Jepang.

Menurunnya pamor komik Indonesia tersebut juga membuat semakin menurunnya komik yang mengangkat sejarah dan budaya nasional, terutama yang mengangkat era kolonial Belanda, yang tidak terlalu banyak dapat ditemukan. Di antara sedikitnya komik bertema sejarah dan kebudayaan Indonesia tersebut, muncullah komik serial 'Legenda Sawung Kampret'. Komik tersebut dibuat oleh Dwi Koendoro, komikus Indonesia yang lebih dikenal sebagai pencipta komik 'Panji Koming', yang dimuat setiap minggu oleh Harian Kompas. Komik 'Legenda Sawung Kampret' menggambarkan situasi Batavia pada masa kolonial VOC abad ke-17 dan sempat dimuat pada majalah 'Humor'.

Berdasarkan pemaparan di atas, dirasakan adanya kebutuhan untuk melakukan studi tentang visualisasi sejarah dan budaya pada komik Indonesia yang bertema sejarah, dengan studi kasus komik serial 'Sawung Kampret', yang dapat dilakukan melalui proses analisis terhadap visualisasi tradisi dan sejarah yang tergambar, baik melalui para tokoh, latar tempat dan waktu serta alur cerita beserta pesan tentang nilai-nilai yang berharga.

\section{Tujuan dan Keutamaan}

Artikel ini dibuat berdasarkan penelitian yang bertujuan mengungkapkan visualisasi pada komik bertema sejarah Indonesia, khususnya 'Legenda Sawung Kampret', yaitu bagaimana komik tersebut menampilkan unsur-unsur sejarah dan tradisi yang tercermin melalui gambaran tokoh, latar tempat maupun waktu serta alur cerita, sehingga dapat memberikan pesanpesan tertentu kepada pembaca yang merupakan generasi muda, terutama agar 
lebih dapat memahami dan berempati pada perjuangan pada periode serjarah Indonesia, serta lebih mengapresiasi kebhinekaan yang dimiliki oleh bangsa Indonesia.

Tujuan tersebut menjadi penting karena di masa kini terdapat indikasi menurunnya minat baca terutama menghadapi persaingan dengan media lainnya, seperti film, TV, multimedia, game dan lainnya. Demikian pula dengan terjadinya penurunan terhadap pemahaman dan apresiasi akan kebhinekaan serta kebanggaan terhadap sejarah perjuangan bangsa. Dengan demikian, kajian tentang visualisasi dalam komik bertema sejarah dan kebudayaan ini diharapkan dapat menghasilkan suatu masukan bagi para illustrator, khususnya yang berkecimpung pada industri komik agar semakin banyak komik bertema sejarah dan kebudayaan dapat diterbitkan dan dibaca oleh generasi muda. Selain itu penelitian ini juga dapat dijadikan referensi ataupun batu pijakan untuk penelitian-penelitian lebih lanjut.

\section{Metodologi}

Sebagai metodologi penelitian dilakukan proses penelusuran kajian-kajian mengenai berbagai referensi, terutama untuk memperoleh berbagai pendekatan artistik tentang cerita dan komik serta sejarah dan kebudayaan Indonesia. Selain itu dilakukan pula penelusuran terhadap kajian-kajian tentang metode penceritaan dan visual dalam komik serta makna elemen dan prinsip dasar visualnya. Hal tersebut akan digunakan sebagai tolok ukur bagi contoh komik yang dijadikan objek penelitian. Dengan demikian dapat diperoleh hasil analisis tentang visualisasi sejarah dan kebudayaan pada komik bertema sejarah tersebut. Diutamakan pula penelusuran terhadap studi kasus, yaitu komik serial 'Legenda Sawung Kampret', yang khususnya mengangkat seorang tokoh pendekar yang hidup di Batavia pada masa pendudukan VOC Belanda yaitu sekitar abad ke-17.

Berdasarkan data yang diperoleh dilakukan analisis deskriptif terhadap elemen dan prinsip visual komik, terutama dari segi penokohan, latar tempat dan waktu, alur cerita serta pesan edukasi sesuai peristiwa sejarah sehingga diharapkan dapat diperoleh suatu masukkan tentang tampilan visualisasi sejarah dan kebudayaan Indonesia terutama dari segi penokohan, latar tempat dan waktu, alur cerita serta pesan edukasi sesuai dengan sejarah dan kebudayaan Indonesia yang terjadi.

Kerangka pemikiran dalam artikel ini dapat dilihat pada Bagan 1 berikut ini.

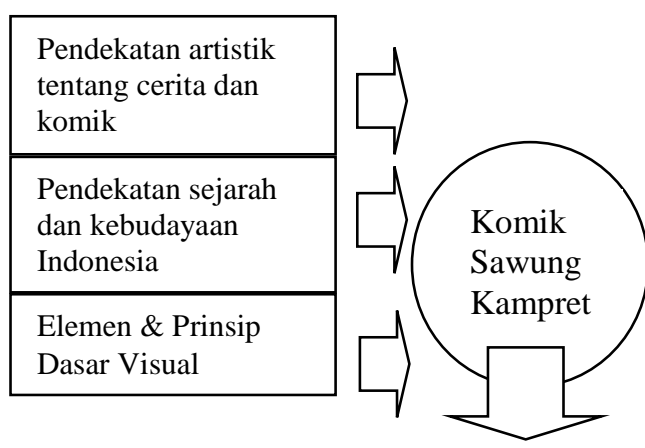

Tampilan visualisasi sejarah dan kebudayaan Indonesia terutama dari segi penokohan, latar tempat dan waktu, alur cerita serta pesan edukasi sesuai dengan sejarah dan kebudayaan Indonesia yang terjadi.

\section{Bagan 1. Kerangka Pemikiran}

\section{Legenda Sawung Kampret}

Serial komik 'Legenda Sawung Kampret' merupakan karya Dwi Koendoro yang diterbitkan oleh Penerbit Mizan. Komik ini dikompilasi berdasarkan komik berseri yang dimuat pada majalah 'Humor' pada tahun 1990. Serial 'Legenda Sawung Kampret' yang diterbitkan dalam beberapa judul, dan yang akan dibahas dalam artikel ini berjudul:

- Legenda Sawung Kampret (bagian 1): Legenda Keturunan Panji Koming diterbitkan Penerbit Mizan, Bandung

- Legenda Sawung Kampret (bagian 2): Pendekar Baju Belang dan Pipi Tembem diterbitkan Penerbit Mizan, Bandung 
Sampul dari kedua buku dapat dilihat pada gambar 1. Sampul Depan 'Legenda Sawung Kampret' Jilid 1 dan 2 berikut ini.
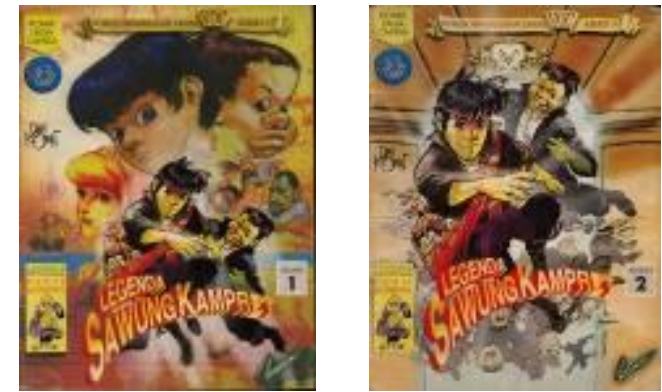

Gambar 1. Sampul Depan 'Legenda Sawung Kampret' Jilid 1 dan 2

Sinopsis dari cerita ini adalah sebagai berikut. VOC yang merupakan singkatan dari Vereenidge Oostindische Compagnie, adalah asosiasi dagang Belanda yang dibentuk oleh Heeren pada awal abad ke-17, dengan tujuan memonopoli perdagangan rempah-rempah, seperti lada, pala, cengkih, di dunia. Saat itu Belanda bersaing dengan bangsa Eropa lainnya, seperti Spanyol, Inggris dan Portugis. VOC biasanya diketuai oleh Gubernur Jendral yang berkantor di Batavia. Di antara serangkaian Gubernur Jendral yang pernah memimpin, salah seorang diantaranya yang dikenal sangat kejam adalah Jan Pieterzoon Coen, yang memerintah antara 1587-1629. Pada masa itu ia mulai membangun kota Batavia, walaupun banyak terjadi masalah pada masa pemerintahannya.

Pada komik ini diceritakan riwayat Sawung Kampret, tokoh utama cerita dan temannya, Na'ip kerap membuat masalah. Nenek moyang Sawung Kampret diceritakan merupakan Panji Koming dan Pailul, yang hidup pada periode Kerajaan Majapahit. Panji Koming dan Pailul mewariskan keris 'Sawung Kampret' pada keturunannya, yang akhirnya saat masuknya bangsa Portugis keris tersebut dirampas oleh tentara Portugis dari tangan ayah Sawung Kampret, seorang pendekar dari Surabaya. Bahkan ayahnya tewas dalam pergulatan tersebut. Sesuai pesan terakhir ayahnya, Sawung Kampret berguru pada sahabatnya, seorang pendekar di Cibadak, Jawa Barat. Di padepokan itulah ia bertemu dengan sahabatnya, Na'ip. Pada usia remaja mereka pergi ke Sunda Kelapa untuk menemui Tan Ping San dan Doktor Van Klompen yang akhirnya mengurus mereka bersama Bang A'um dan Nek Isah. Mereka kerap menolong penduduk sekitar dari terror para jawara yang suka merongrong. Pada masa pemerintahan Gubernur Jendral Jan Pieterzoon Coen, batu prasasti yang dianggap keramat dan merupakan peninggalan Raja Purnawarman akan digusur untuk pembangunan kota. Namun ia harus menghadapi para pendekar yang menjaga batu tersebut. Dengan segala cara yang licik, usaha untu menghancurkan prasasti tersebut berhasil dilakukan dan menewaskan Doktor Van Klompen saat berusaha mempertahankannya. Tentu saja Sawung Kampret dan Na'ip tidak tinggal diam dan berusaha melawan.

Tokoh-tokoh dalam cerita ini antara lain adalah Sawung Kampret, Na'ip bin Jali, Marietje van der Bloemkool, Doktor van Klompen, Fritz van der Bloemkool dan Jan Pieterzoon Coen. Tokoh pendukung lainnya adalah Marutoklopo, Tan Ping San, Bang A'um, Nek Isah, Tiga Serdadu: Kapiten van Tabock, Letnan Markapoetz, Sersan van Sablon, Plenti, Tan Mei Ling, Ni Woro Sendang dan Sarpin.

\section{Analisis Sejarah dan Budaya pada Alur Cerita}

Pada alur cerita 'Legenda Sawung Kampret' terdapat alur mundur, yaitu pada Jilid 1 diceritakan mulai ketika Sawung Kampret sudah dewasa dan menikah lalu terdapat penceritaan tentang bagaimana riwayat asal-usulnya bersama $\mathrm{Na}$ 'ip. Alur cerita tentang riwayat Sawung Kampret mulai diceritakan sejak masa Kerajaan Majapahit, masa hidup nenek moyangnya, Panji Koming dan Pailul, yaitu pada pemerintahan Raja Wikramawardhana (1389-1427). Alur berlanjut hingga muncul riwayat orang tua Sawung Kampret, yang akhirnya tewas di tangan serdadu Portugis. Ketika itu Sawung Kampret masih kanakkanak, hingga akhirnya ia harus berkelana 
dari tempat tinggalnya di Surabaya menuju Cibadak, Jawa Barat, melalui Kerajaan Mataram, yang waktu itu dipimpin oleh Sultan Agung Hanyokrokusumo (16131645).

Perjalanan Sawung Kampret berlanjut dari Cibadak, tempatnya berguru pada pendekar Badakngajentul dan bertemu dengan Na'ip sahabatnya, menuju Sunda Kelapa, membuatnya bertemu dengan Gubernur Jendral Jan Pieterzoon Coen (1587-1629), yang sedang berusaha membangun kota Batavia, dengan menggusur prasasti peninggalan Raja Purnawarman dari Kerajaan Tarumanegara. Pada akhirnya Sawung Kampret, Na'ip dan pendukungnya berhasil menahan serbuan Jan Pieterszoon Coen.

Visualisasi dari alur cerita tersebut dapat dilihat pada bagian komik tercantum dalam Gambar 2 berikut ini.

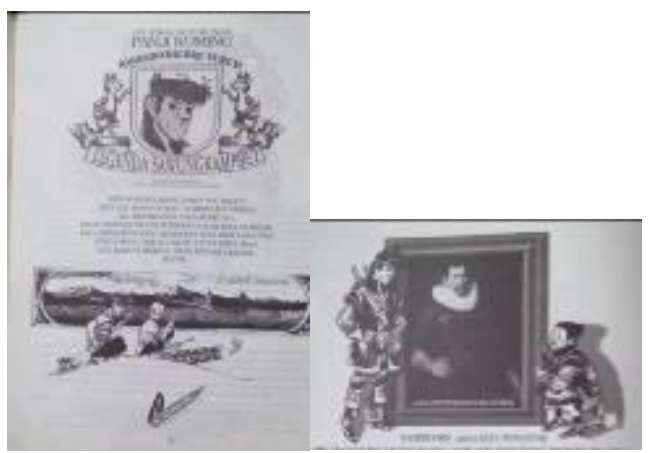

Gambar 2. Halaman Judul

Bingkai yang menghiasi gambar profil Sawung Kampret menggunakan pendekatan logo yang banyak digunakan di Eropa pada abad ke 18-19, yaitu latar berbentuk perisai dan figur di samping kanan dan kiri serta tulisan dalam pita pada bagian bawah. Demikian pula dengan lukisan Jan Pieterszoon Coen yang menggunakan gaya Romantisisme, yang timbul di Eropa sekitar abad 18-19, dengan bingkai berprofil. Hal ini memperkuat latar belakang sejarah yang menjadi setting waktu dari cerita ini.

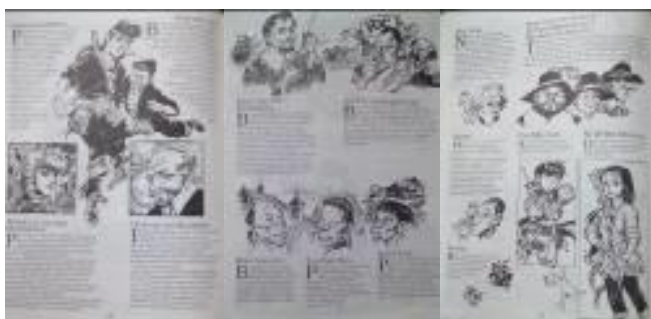

Gambar 3. Halaman Perkenalan Tokoh

Untuk mendukung latar sejarah dan budaya, dalam penggambaran para tokohnya, kostum, tata rambut dan atribut lainnya disesuaikan dengan asal kebudayaan yang melatarinya dan periode sejarahnya. Hal ini dapat dilihat pada Gambar 3. Halaman Perkenalan Tokoh. Latar tempat seperti kerajaan Majapahit

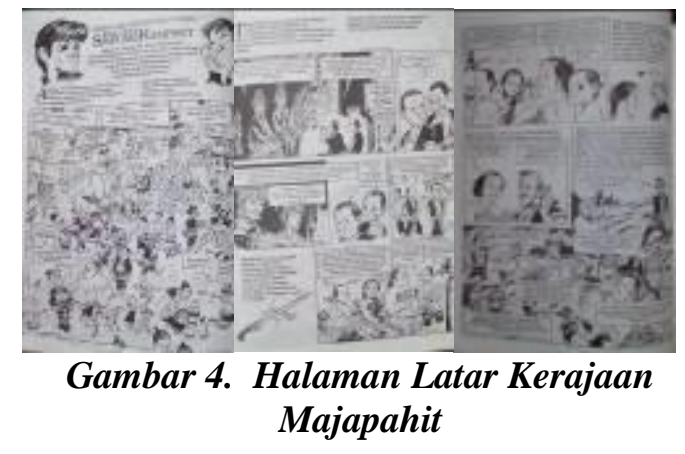

\section{Analisis Sejarah dan Budaya pada Penokohan}

Pada cerita Legenda Sawung kampret para tokoh diperkenalkan terlebih dahulu. Hal ini dapat dilihat pada Gambar 3. Bahkan Jan Pieterszoon Coen sebagai tokoh nyata yang memiliki lukisan potret diri sebagai dokumentasi diberikan gambarannya pada halaman judul. Selain tokoh-tokoh yang telah diperkenalkan pada awal cerita, ada pula tokoh-tokoh nyata yang memang tercatat dalam sejarah Indonesia, misalnya adalah Raja Majapahit Wikramawardhana, Raja Mataram Sultan Agung, sementara tokoh-tokoh lainnya merupakan rekaan.

Pada umumnya para tokoh disajikan dengan kostum yang sesuai dengan periodenya. Pada kostum para pembesar Belanda, misalnya disesuaikan dengan penelusuran referensi yang sesuai 
dengan periodenya. Kostum yang digunakan oleh para pejabat maupun serdadu Belanda digambarkan seperti kostum yang tampak pada lukisan-lukisan Belanda. Misalnya yang dapat dilihat pada Gambar 2. Halaman Judul.

$\begin{array}{rrr}\text { Demikian } & \text { pula dengan kostum } \\ \text { kebesaran } & \text { Raja } & \text { Majapahit }\end{array}$
Wikramawardhana, serta kostum para tokoh bersuku bangsa Tionghoa. Bahkan bakiak yang dikenakan oleh penduduk lokal mengikuti bentuk alas kaki yang dikenakan saat itu. Hal ini dapat dilihat pada sandal yang menjadi koleksi Museum Nasional Indonesia pada Gambar 5. Sandal Bakiak berikut.

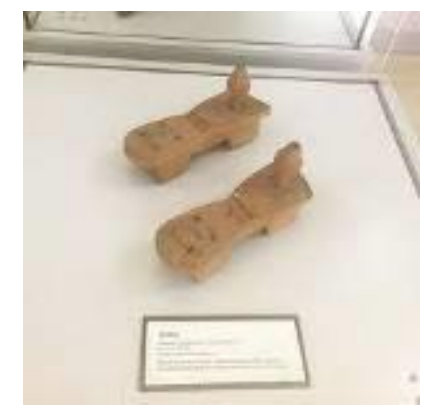

\section{Gambar 5. Sandal Bakiak}

Sementara itu Sawung Kampret digambarkan mengenakan baju pangsi dan ikat kepala, seperti yang dikenakan oleh masyarakat Jawa pada masa kolonial Belanda. Selain itu ia mengenakan baju bermotif belang-belang, ternyata ketika masih diterbitkan dalam bentuk serial majalah telah menerima masukan bahwa pada periode tersebut belum ada baju seperti itu, namun pada cerita dalam buku komik baju tersebut dijelaskan dalam penceritaan bahwa baju tersebut diberi belang agar berbeda dengan baju Na'ip sehingga tidak tertukar.

\section{Analisis Sejarah dan Budaya pada Latar Waktu dan Tempat}

Sesuai dengan latar waktu dan tempat, komik ini membahas mengenai Batavia pada abad ke-17, tepatnya pada saat VOC mulai berkembang di Batavia. Periode waktu tersebut dipertegas dengan pita yang dipakai sebagai dasar judul
'Legenda Sawung Kampret' dengan bentuk perisai berisi gambar profil wajah Sawung Kampret sebagai tokoh utama cerita, yang dapat dilihat pada halaman judul. Pada halaman judul tersebut juga terdapat gambaran tentang Kastil Batavia yang diberi frame sesuai gaya periode Abad Pertengahan. Gambaran tempat, sesuai dengan cerita misalnya kota Majapahit digambarkan dengan agak detail sebagai pusat kerajaan yang sangat ramai.

\section{Analisis Sejarah dan Budaya pada Pesan Cerita}

Kampret, meskipun diberikan tema perlawanan bangsa Indonesia, yang diwakili oleh Sawung Kampret dan Na'ip, ternyata tersirat pesan multikulturalisme. Dalam komik ini digambarkan bahwa Sawung Kampret, meskipun merupakan cucu moyang dari Panji Koming dan Pailul yang berasal dari Kerajaan Majapahit di Jawa Timur, ternyata keturunannya telah bercampur baur suku bangsa, mulai dari Batak, Padang, Aceh dan lainnya lagi. Tidak berhenti di situ, Sawung Kampret harus berguru pada pendekar bersuku Sunda. Sawungkampret juga dekat bahkan dengan Dokter van Klompen, yang berkebangsaan Belanda dan Tan Ping San yang Tionghoa. Berdasarkan hal itu dapat diambil kesimpulan bahwa meskipun terdapat pertikaian antara suku bangsa, tetapi kadang hal tersebut tidak mewakili semua pribadi secara keseluruhan. Ada orang Belanda yang juga berniat baik dan menghargai masyarakat lokal. Tetapi justru ada pula sesama bangsa Indonesia yang malah berkhianat dan mengadu domba bangsa sendiri, seperti tokoh Marutoklopo.

\section{SIMPULAN}

Dapat disimpulkan bahwa sejarah dan budaya yang tergambar pada komik 'Legenda Sawung Kampret' tergambar sesuai dengan referensi sejarah dan budaya yang menggambarkan pakaian, kota, serta aspek ornamen pada komik ini. Dalam mengangkat para tokoh juga tampak 
disesuaikan dengan tokoh yang memang tercatat dalam sejarah walaupun tokoh nyata hanya beberapa. Sementara itu pesan yang diberikan dalam komik ini, sekalipun terdapat pendekatan sejarah yaitu mengenai penjajahan Belanda, yang diwakili oleh VOC, pesan dari komikus antara lain justru mengenai toleransi terhadap pluralisme yang diwakili oleh gambaran bangsabangsa yang mendukung tokoh utama Sawung Kampret. Demikian pula bahwa tidak selamanya permusuhan yang melibatkan dua bangsa atau lebih, merupakan permusuhan antara dua bangsa secara mutlak, karena dibalik dua bangsa yang berbeda dan bermusuhan seringkali terdapat pribadi-pribadi yang teguh pada kebenaran dan melupakan aspek perbedaan kultur.

\section{DAFTAR PUSTAKA}

Bonneff, Marcel. 2008. Komik Indonesia. Jakarta: Kepustakaan Gramedia Utama.

Darmaprawira, Sulasmi. 2002. Warna, Teori dan Kreativitas Penggunaannya. Bandung: ITB

Dwi Koendoro. Legenda Sawung Kampret : Bagian 1. Bandung: Mizan

Dwi Koendoro. Legenda Sawung Kampret: Bagian 2. Bandung: Mizan

Eisner, Will. 2008. Graphic Storytelling and Visual Narative: and Practices from The Legendary Cartoonist

(Will Eisner Instructional Book).

NY: W. W. Norton \& Company

Eisner, Will. 2008. Comic and Sequential

Art: Principles and Practices from

The Legendary Cartoonist (Will

Eisner Instructional Book). NY: W.

W. Norton \& Company

Kusrianto, Adi. 2007. Pengantar Desain

Komunikasi Visual. Yogyakarta:

Andi

Kusmiati, Artini; Pudjiastuti, Sri ; Suptandar, Pamudji. 1999.Teori Dasar Disain Komunikasi Visual. Jakarta: Djambatan

McLoud, Scott. 1994. Understanding Comics: The Invinsible Art. NY: William Morrow Paperbacks

Sachari, Agus. 1998. Tinjauan Desain. Bandung: ITB

Wallschlaeger, Charles; Busic-Snyder, Cynthia. 1992. Basic Visual Concepts and Principles for Artists, Architects, and Designers. Ohio: Ohio State Uni versity

\section{Sumber Lain :}

http://sejarahri.com/sejarah-komikindonesia/ 